\title{
EM DEFESA DA VIDA: UM OLHAR INTEGRANDO HANNAH ARENDT, ECOLOGIA INTEGRAL E CULTURA BÍBLICO-HEBRAICA
}

IN DEFENSE OF LIFE: AN INTEGRATING LOOK AT HANNAH ARENDT, INTEGRAL ECOLOGY AND BIBLICAL-HEBRAIC CULTURE

EN DEFENSA DE LA VIDA: UNA MIRADA INTEGRANDO HANNAH ARENDT, ECOLOGÍA INTEGRAL Y CULTURA BÍBLICA HEBRAICA

\section{Noli Bernardo Hahn'}

\section{Jacson Roberto Cervi}

Licença CC BY:

Artigo distribuído sob os termos Creative Commons, permite uso e distribuição irrestrita em qualquer meio desde que $o$ autor credite a fonte original.

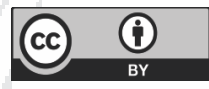

Palavras-chave: Ecologia integral; Cultura bíblico-hebraica; Defesa da vida; Direito; Hannah Arendt.

\begin{abstract}
Resumo: A questão problematizadora ao tema central do artigo se delimita nesta pergunta: Qual é o núcleo temático pelo qual se relacionam a cultura bíblico-hebraica, Hannah Arendt e Ecologia Integral, tendo a defesa da vida como o horizonte dessa relação? Como resposta, foca-se na diversidade e na pluralidade como núcleos temáticos para estabelecer esta relação. Centra-se na interação, na interdependência e na inter-relação do diverso e do plural como determinantes para a defesa da vida em sua dimensão e sentido lato (amplo) e stricto (restrito), ao mesmo tempo. Apontase Ecologia Integral como um conceito e uma categoria de compreensão que emerge num novo paradigma científico, em que não se compreende apenas pela analysis, que pressupõe separação, disjunção e o controle do conhecido, para poder explicar o que se conhece pela disjunção, mas se pressupõem relações que não se disjuntam. Este paradigma projeta desafios ao Direito.
\end{abstract}


Abstract: The research question at the heart of this article can be summarized as follows: What is the thematic nucleus that links Biblical-Hebraic culture, Hannah Arendt and Integral Ecology, the end goal of this relationship being the defense of life? In a response to this question, it focuses on diversity and plurality as thematic nuclei to establish this relationship. It focuses on the interaction, interdependence and interrelationship of the diverse and plural as determinants for the defense of life in its dimension and in its lato senso (broader sense) and stricto senso (restricted sense), simultaneously. Integral Ecology is indicated as a concept and a category of understanding that emerges in a new scientific paradigm, in which it is not only understood by analysis, which presupposes separation, disjunction and the control of the known, to be able to explain what is known by the disjunction, but rather, it presupposes relations that do not separate. This paradigm poses challenges to the Law.

keywords: Integral Ecology; Biblical-Hebrew culture; Defense of life; Right; Hannah Arendt.

Resumen: La cuestión problematizadora al tema central del artículo se delimita en esta pregunta: ¿Cuál es el núcleo temático por el cual se relaciona la cultura bíblica hebraica, Hannah Arendt y Ecología Integral, con la defensa de la vida como el horizonte de esta relación? Como respuesta, se enfoca en la diversidad y en la pluralidad como núcleos temáticos para establecer esta relación. Se centra en la interacción, en la interdependencia y en la interrelación de lo diverso y de lo plural como determinantes para la defensa de la vida en su dimensión y sentido lato (amplio) y stricto (restricto), al mismo tiempo. Se apunta Ecología Integral como un concepto y una categoría de comprensión que emerge en un nuevo paradigma científico, en que no se comprende apenas por el analysis, que presupone separación, disyunción y el control de lo conocido, para poder explicar lo que se conoce por la disyunción, pero se presuponen relaciones que no son disyuntivas. Este paradigma proyecta desafíos al Derecho.

Palabras clave: Ecología integral; Cultura bíblica hebraica; Defensa de la vida; Derecho; Hannah Arendt.

\section{INTRODUÇÃO}

Defender a vida foi e continua sendo uma das grandes batalhas do ser humano. A defesa da vida, sem dúvida, é um objetivo nuclear do viver humano. Os vetores centrais do animus humano, ou seja, de toda vitalidade humana, relacionam-se com a defesa da vida. Palavras como esperança, fé, amor, paixão, compaixão, justiça, misericórdia, direito, termos centrais de literaturas já de povos antigos, interfaceiam-se em seus sentidos e seus múltiplos significados com defesa da vida. ${ }^{4}$

Em meio a tantos sinais e realidades de morte, o ser humano acende os faróis da esperança e continua acreditando na vida, regando a sua fé com pequenos sinais de compaixão e misericórdia e lutando, ao mesmo tempo, por um direito que tenha como finalidade a justiça. Não é, no entanto, qualquer justiça que o desejo humano, verdadeiramente humano, deseja e almeja. Por longos séculos, e até milênios, inspirado por uma concepção metafísica de unidade do ser, investiu-se em uniformizar

4 Aqui, faz-se menção a textos que provêm da literatura bíblico-hebraica. Nesta literatura, há distintos gêneros literários. Destacam-se, nesta menção, a literatura profética e a literatura sapiencial. A literatura profética é uma literatura que provém da resistência contra todo tipo de injustiças e violências praticadas por pessoas, coletividades e, especialmente, pelo Estado. Os profetas são lideranças que leem tais injustiças e defendem a vida de quem está sendo vítima de violências, das mais variadas. Nos textos conhecidos como sapienciais, o sábio concebe a defesa da vida em distintas formas. Uma delas, como já se está em contexto grego dos séculos V ao I antes de Cristo, é um cuidado com o pensamento. Aí já se previnem maldades humanas alertando para formas e jeitos de raciocínio, concepções teológicas que enganam as pessoas, a idolatria, etc. 
e homogeneizar o ser humano. ${ }^{5}$ Muitas culturas organizaram-se eliminando pluralidades, diferenças e diversidades. As políticas mais extremas e catastróficas, neste viés filosófico, mostraram-se no nazismo, no fascismo e no stalinismo. Os Estados Totalitários são o exemplo mais claro e evidente de propostas uniformizadoras e homogeneizadoras do humano. O eurocentrismo, igualmente, postula a morte e a eliminação de muitos povos ao longo de uma política colonialista. Hoje, tem-se a consciência de que o desejo verdadeiramente humano almeja uma justiça que consiga conceber humanidade a partir da diversidade, da pluralidade e do reconhecimento da diferença. ${ }^{6}$ Defender a diversidade humana e as formas plurais de convivência humana impõe-se como um imperativo ético central do existir humano. Da mesma forma, defender a diversidade e a pluralidade interativa, auto-organizativa e interdependente do fenômeno vida, em sua dimensão holística, ampla e sistêmica, integrando todos os seres vivos, todas as plantas, todos os elementos naturais, todo o sistema cósmico, constitui-se num entendimento novo que a ciência desenvolvida, especialmente no século $X X$, propicia a nós neste início do século XXI.7 Este novo entendimento amplifica, também, o conceito de justiça e desafia os povos e as nações a rever e a atualizar os seus sistemas normativos, ou seja, o direito. Nesta noção de justiça amplificada, o imperativo ético não se centra apenas na diversidade e na pluralidade humanas, mas integra, também, a diversidade da vida em sua dimensão holístico-integral. 8

Neste artigo, pretende-se, sob uma ótica integrativa, relacionar Hannah Arendt, Ecologia Integral e elementos da cultura hebraica sob o horizonte da defesa da vida. A questão-problema delimita-se na seguinte pergunta: Qual é o núcleo temático pelo qual se possa relacionar a cultura bíblico-hebraica, Hannah Arendt e Ecologia Integral, tendo a defesa da vida como o horizonte dessa relação?

Argumenta-se a resposta a esta pergunta focando a diversidade e a pluralidade como núcleos temáticos para estabelecer esta relação. A interação, a interdependência e a inter-relação do diverso e do plural são determinantes para a defesa da vida em sua dimensão e sentido lato (amplo) e stricto (restrito) ao mesmo tempo. Concebe-se a humanidade em sua diversidade e pluralidade como, também, todo o fenômeno da vida, procurando argumentar que a humanidade se encontra integrada neste fenômeno vital. Ao se recorrer ao verbo integrar para explicitar a relação entre o humano e a vida não humana, parte-se da premissa da inexistência de vida humana fora do fenômeno vida em

5 Os filósofos conhecidos como pós-estruturalistas esclarecem esta face com muita evidência. Pode-se citar, especialmente, Jacques Derrida e Gianni Vattimo. Em Referências citam-se algumas obras que o leitor poderá consultar sob esta perspectiva.

6 Lendo os livros de Hannah Arendt, esta é uma ideia central que perpassa sua obra. Na visão da autora, humanidade não se pode conceber a partir de uma ideia abstrata e procurar aplicá-la no convívio humano. A ideia de humanidade só pode conceber-se a partir de um olhar indutivo, reconhecendo-se a diversidade e a pluralidade da espécie humana.

7 A obra de Edgar Morin, teorizando o paradigma da complexidade, pode ser lembrada como um marco teórico para se construir uma consciência de inter-relações e de interdependências em processos auto-organizativos.

8 Neste horizonte de ampliação da responsabilidade, fala-se, também, em direitos da natureza, em que o ser humano terá de se responsabilizar para defender os direitos de quem não tem voz para defender-se. Porém, ao primar pelos direitos da natureza, cria-se a consciência da autodefesa, ou seja, ao defender a natureza, o ser humano protege-se de sua autodestruição. 


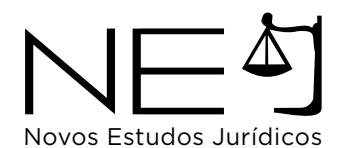

sua dimensão holística. Por esta concepção integrativa perpassa toda a reflexão que segue. Procurase focalizar alguns temas refletidos por Hannah Arendt que se mesclam com o que se compreende hoje por Ecologia Integral e integram-se alguns elementos da cultura hebraica que coincidem com a compreensão da defesa da vida pelo olhar do respeito e do reconhecimento da dinâmica integrativa da pluralidade e da diversidade que se evidencia no fenômeno vida.

\section{UM OLHAR INTEGRANDO HANNAH ARENDT}

Hannah Arendt escreveu suas obras num momento histórico em que a vida humana, em sua diversidade e pluralidade, estava sendo, de um lado, negada e, por outro, imperativamente defendida. A consciência da necessidade da defesa da vida humana emerge em um contexto em que milhões de pessoas são mortas, não apenas por outras pessoas, mas por uma estrutura tecnológica altamente sofisticada e por uma estrutura mental axiológica de morte elaborada durante séculos. O Estado Totalitário representa a conexão entre uma estrutura mental axiológica e uma estrutura tecnológica que permite e executa a morte, fazendo com que as pessoas não se veem e não se sentem responsáveis pelos seus atos. ${ }^{9}$

É neste contexto, também, que Martin Heidegger ${ }^{10}$ escreve distinguindo entre um pensamento tecnológico-calculador e um pensamento reflexivo e meditativo. O pensamento calculador é um pensamento pobre. Este pensamento, além de não dar conta de defender a vida, ajuda para que esta não seja defendida. Uma razão da pobreza desse pensamento não meditativo é a relação epistemológica que subjaz a sua lógica: a relação é a de sujeito versus objeto, na qual o objeto é manipulado a partir e em função do sujeito, estabelecendo-se uma relação de domínio, de violência e de destruição. Outra razão da pobreza do pensamento calculador é a negação da perspectiva inter-relacional, interativa, auto-organizativa e interfacial que se reconhece, hoje, a partir de um pensamento complexo-paradoxal e sistêmico do fenômeno vida. ${ }^{11}$

Focando na obra de Hannah Arendt, é condição humana sermos seres de linguagem e seres terrenos. Esta condição de conexão entre terra e linguagem, na qual o ser humano se identifica e cria efetivamente sua identidade, integra a necessidade de uma relação reflexiva e meditativa constante para não se desconectar esta relação. No livro $A$ condição humana, três categorias de compreensão são fundamentais para se compreender esta identidade e condição humana. As categorias são estas: labor, trabalho e ação.

9 Ao ler, especialmente, o livro Origens do Totalitarismo, Hannah Arendt explicita esta conexão. O movimento totalitário consegue anular um horizonte axiológico, em que se anulam a pessoalidade, a relacionalidade, e se imprime um novo horizonte axiológico de lealdade incondicional ao Führer, o Guia que guia a história. Nesta lealdade incondicional, a estrutura tecnológica de morte não é problematizada, pelo contrário, esta estrutura está a serviço de um plano axiológico que conduz a história, sendo esta guiada pelo desejo do Führer.

10 HEIDEGGER, Martin. Serenidade, 1955.

11 Volta-se a enfatizar que a consciência da interdependência consiste numa consciência em que cresce a responsabilidade pelo cuidado da vida, em sua dimensão ampla e sistêmica, incluindo toda a natureza. 
Labor estabelece a condição terrena. Todo o processo biológico do corpo humano, suas necessidades vitais, suas identificações com a terra expressam-se pelo termo Labor. Trabalho e a ação relacionam-se com linguagem. Desta conexão profunda e umbilical entre terra e linguagem decorre um entendimento do que é viver. Viver é estar entre. Viver é estar relacionado com o fenômeno vida, numa dimensão holística e numa dimensão particularizada, singular, ao mesmo tempo. Viver é estar entre os outros seres humanos que, pela sua condição terrena, não se encontram desconectados de todo fenômeno vital. Viver, portanto, é estar entre, mantendo relações vitais com a vida em sua amplitude de conexões, inter-relações e interações. Labor não pode ser desconectado de trabalho e ação, como, também, trabalho e ação não podem ser separados de labor.

Não há vida humana, portanto, na atomização e no isolamento. Integrando uma noção crítica à ciência moderna, esta fez história desconectando o ser humano de si, dos outros humanos e da natureza. Isolar, separar, disjuntar, constituem-se ações analíticas de uma cientificidade que fez história e, de certa forma, continua fazendo, durante séculos. Mesmo que houve descobertas e progressos para a humanidade, como resultados desse paradigma científico, há de se manter o cuidado e a crítica de o processo disjuntivo não se tornar cultura na humanidade.

Esta noção de que não há vida humana em processos de atomização e isolamento é central para toda a crítica ao movimento totalitário que Hannah Arendt descreve e reflete no livro Origens do Totalitarismo. O entre é decisivo para a humanidade. Criar e construir a consciência do entre é um imperativo para não se perder a humanidade e não se perder a conexão com a vida, em sua dimensão ampla, em que se relacionam labor, trabalho e ação.

Ao se ler o livro Origens do Totalitarismo, constata-se um processo de construção do ódio e da hostilidade. Neste processo cultural de elaboração e de endoculturação da hostilidade e do ódio, há um rompimento e uma negação da consciência do entre. Este processo é histórico, é uma construção de séculos e de décadas. O ódio e a hostilidade são frutos de aprendizagem. O nazismo, o fascismo e o stalinismo, todos do século XX, evidenciam-se numa construção de décadas e décadas. De centenas de anos. Os netos, os bisnetos, os tataranetos executaram o que foi construído durante muitos anos pelos avós, bisavós e tataravós. O ódio e a hostilidade foram sendo gerados geracionalmente. Esta construção se deu de várias formas. Uma forma a se destacar, descrita no livro Da Violência, foi por meio de teorias que identificavam e relacionavam Poder e Violência. Vários autores são mencionados e suas teorias criticadas e desconstruídas, exatamente porque compreendiam que o poder e a violência eram realidades que emergiam da mesma fonte. Hannah Arendt, neste livro, argumenta que a natureza e a causa da violência não se relacionam com a emergência de poder. A natureza do poder não se equaciona com a natureza da violência. A violência não produz poder. O poder, 
também, não produz violência. A violência não se gera do poder e o poder também não se gera da violência. A natureza da violência é instrumental. A natureza do poder é a relação. O poder se gera da dimensão entre.

No livro Da Violência pode-se constatar e conceber o quanto teorias ajudam para fortalecer e fomentar uma cultura. Desconstruir teorias é fundamental para não se continuar um processo de destruição da humanidade e de todo o fenômeno vital que, no caso, acontece quando se elaboram teorias que partem do pressuposto de que a humanidade e todo sistema vida não é relacional. Relacionar, inter-relacionar, interfacear, interdepender, auto-organizar, constituem-se ações de um novo paradigma de entendimento da vida humana e da vida em sua dimensão sistêmica interrelacionada.

A perspectiva relacional constitui-se, ao mesmo tempo, na ótica de Hannah Arendt, em um método, num jeito de ser e num conteúdo central de construção do que é humano e do que é vital.12 Relacionar-se consigo, em processos meditativos e reflexivos, significa, também, relacionar-se com os outros e com toda a natureza, porque, pela dimensão laborosa, somos natureza. Esta tese, no entanto, não deverá justificar um determinismo biológico para o que se constrói relacionalmente. A violência, já se argumentou anteriormente, não pode ser motivada e causada desde a mesma fonte da qual emerge o poder. Somos natureza, porém pela linguagem construímos uma identidade específica do humano, que se evidencia na e pela ação e pelo trabalho, sem, jamais, perder a conexão com labor.

O Movimento Totalitário, descrito no livro Origens do Totalitarismo, é um movimento axiológico, de eliminação de todos os valores em que haja relações humanas. Solidariedade, consciência de classe, família, fraternidade, cooperação, são palavras que não significam mais nada num processo de movimento totalitário. Há uma aniquilação das relações humanas. Qual a finalidade última da aniquilação das relações? A Lealdade total ao Líder totalitário. O grande valor é a Lealdade. Lealdade não a uma Constituição, mas ao DESEJO do Führer (Guia). Num movimento totalitário, o movimento axiológico que se mostra é o de anulação completa do sujeito individuado. O movimento totalitário elimina completamente processos de subjetivação, de individuação e de autonomização. ${ }^{13}$ A pessoa não se relaciona mais nem consigo, nem com outros humanos e é destituída de uma relação com a vida, em sua dimensão mais holística.

12 Esta constatação é possível, lendo-se a obra de Hannah Arendt, relacionando suas principais teses. Destaca-se, no entanto, o livro Origens do Totalitarismo.

13 Para entender o que significam processos de subjetivação, Alain Touraine é um autor importante a ser estudado. Em Referências indicam-se livros em que este tema é refletido. 
Ao ser destituído de sua relacionalidade, o ser humano emerge em sua desumanidade num e através de um coração de trevas, ${ }^{14}$ sendo este coração um resultado da confluência de capacidade destrutiva e da burocratização da vida pública. O termo Banalidade do Mal é um conceito e uma categoria de compreensão que aparece no livro Eichmann em Jerusalém. O sentido e o significado deste termo emergem da consciência do mal presente num contexto histórico, no entanto um coração de trevas desumanizado o executa pela confluência da burocracia e da violência de natureza instrumental, inerente a uma lealdade absoluta ao desejo do Führer (Guia Totalitário). Neste viés, em Hannah Arendt, surge a categoria tempos sombrios. Os tempos sombrios são tempos em que há uma atomização e um isolamento total do ser humano. Tempos sombrios são tempos em que se anulam e se dizimam relações. Tempos em que o mal deixa de ser reconhecido como tal pelas pessoas, dado o efetivo processo de normalização e a legalização das práticas de segregação, culminando com a permissividade do extermínio em massa.

Nos ensaios biográficos, editados no livro que recebe o título de Homens em tempos sombrios, perpassa uma crença na solidariedade e na dignidade humana, valores morais capazes de impedir o triunfo da descrença total numa época de experiências catastróficas. Fazer renascer a chama da crença nas relações mostra-se, numa dimensão antropológica, pedagógica e escatológica, num ato de emancipação, de libertação e de salvação da humanidade.

Em continuidade, traz-se para a reflexão a categoria de compreensão Ecologia Integral no intuito de evidenciar a amplitude de sentidos que esta expressão significa e inter-relaciona. Nos tempos de Hannah Arendt, esta expressão, no sentido como a entendemos hoje, não se encontrava em reflexões escritas em livros ou artigos. No entanto, ao se ler os livros de Arendt, percebe-se, com toda a certeza, que suas reflexões contribuíram para o surgimento desta categoria de compreensão na ciência que se fez nas últimas décadas do século XX e inícios do século XXI.

\section{ECOLOGIA INTEGRAL}

Para este artigo, delimitou-se o tema central por meio desta pergunta: Qual é o núcleo temático pelo qual se possa relacionar a cultura bíblico-hebraica, Hannah Arendt e Ecologia Integral, tendo a defesa da vida como o horizonte dessa relação? Como resposta a esta pergunta, focam-se a diversidade e a pluralidade como núcleos temáticos para estabelecer esta relação. Centra-se na interação, na interdependência e na interrelação do diverso e do plural como determinantes para a defesa da vida em sua dimensão e sentido lato (amplo) e stricto (restrito) ao mesmo tempo.

14 Coração de trevas é uma categoria que se encontra no livro Eichmann em Jerusalém. Nesta expressão há a sistematização da desumanização do ser humano em processos totalitários de atomização e de isolamento. 
Neste momento da reflexão, apresentam-se o conceito e a categoria de compreensão ecologia integral num horizonte de entendimento de uma consciência de cuidado responsável que integra o grito sistêmico e pluriforme da terra e o grito dos pobres e vulneráveis. Ecologia Integral integra, ao mesmo tempo, a ecologia ambiental, a humana, a econômica, a social, a cultural e a ecologia da vida cotidiana. Ecologia Integral nasce como conceito e como categoria de compreensão inerente a um paradigma em que se constroem conhecimentos inter-relacionando saberes de diversas ciências e dentro de saberes que só se concebem saberes pela interconexão. ${ }^{15}$

Ecologia integral consiste num paradigma que une fenômenos humanos e problemas ambientais. ${ }^{16} \mathrm{O}$ pressuposto teórico é o de que tudo está relacionado. Problemas como aquecimento global, poluição, desflorestamento, queimadas em grandes e pequenas proporções, relacionam-se com a habitabilidade dos espaços urbanos ou a superlotação dos transportes públicos, por exemplo. Ecologia Integral não integra apenas preocupações com o verde. Esta dimensão é importante enfatizar: em Ecologia Integral, a casa (oikos) é concebida a partir de multidimensões relacionadas e interdependentes. Ecologia Integral emerge como conceito e categoria de compreensão a partir de uma consciência conectiva.

Ecologia integral, como paradigma17, desafia metodologicamente a uma análise e a uma interpretação integradas, partindo-se do pressuposto de uma raiz comum, ou de uma fonte comum, de fenômenos que, tomados separadamente, não podem ser compreendidos. O Papa Francisco, na Encíclica Laudato Si', neste sentido, alerta:

Não existem duas crises separadas, uma ambiental e outra social, e sim uma só e complexa crise socioambiental. As diretrizes para a solução requerem uma concepção integral para combater a pobreza, para restituir a dignidade aos excluídos e, ao mesmo tempo, para cuidar da natureza. ${ }^{18}$

Na mesma ótica, lê-se, nesta mesma Encíclica, que "não podemos deixar de reconhecer que uma real concepção ecológica se torna sempre uma concepção social que deve integrar a justiça na discussão sobre o ambiente, para escutar tanto o clamor da terra quanto o clamor dos pobres" (n. 49).

Esta concepção ecológica, quando internalizada em nossas vidas cotidianas, muda e transforma nossas relações e nossas posturas. Em realidade, a atenção, em relação ao nosso jeito de nos portar, muda de foco. Vejamos o que escreve o Papa Francisco:

\footnotetext{
15 Para esta compreensão, relevantes são os artigos que compõem a obra: MURAD, Afonso; TAVARES, Sinivaldo Silva (Org.). Cuidar da casa comum. São Paulo: Paulinas, 2017.

16 Uma pesquisa que contempla e integra muitas informações sobre esse tema encontra-se em: CERVI, Jacson Roberto; HAHN, Noli Bernardo. O Cuidado e a Ecologia Integral. In: Direitos Culturais, Santo Ângelo, v.12, n.27, p. 149-172, maio/ago. 2017.

17 O artigo de CERVI, Jacson Roberto; HAHN, Noli Bernardo. A terra pede paz - a emergência do paradigma do cuidado e a superação do paradigma da conquista. In: Revista Internacional de Direito Ambiental. Caxias do Sul: Plenum, n. 15, p. 95-116, set/dez. 2016, traz uma série de elementos que explicitam a diferença entre o paradigma da conquista e o paradigma do cuidado, propiciando entendimentos para se conceber a categoria Ecologia Integral. 
Evitar o uso de material plástico ou de papel, reduzir o consumo de água, diferenciar os rejeitos, cozinhar somente quanto razoavelmente se poderá comer, tratar com cuidado os outros seres vivos, utilizar o transporte público ou compartilhar um mesmo veículo entre várias pessoas, plantar árvores, apagar as luzes inúteis, e assim por diante. ${ }^{19}$

Integrando reflexões do sociólogo francês Alain Touraine ${ }^{18}$, pode-se afirmar que, quando partem de motivações profundas, estes gestos e esta nova postura frente ao cotidiano da vida não são deveres que emergem de uma necessidade verde, mas são um resultado de profundos processos de autonomização, de subjetivação e de individuação, em que o indivíduo, resistindo criativamente contra uma cultura de dessubjetivação, em que se anula e se destrói o sujeito, tornase ator e atriz social. Ecologia Integral torna-se, sob esta ótica, um paradigma em que se constroem sujeitos conscientes de si mesmo, no sentido de cientes das consequências de seus atos cotidianos relacionados a um macrossistema ecossocial.

O cuidado pela terra e o cuidado em relação ao vulnerável e ao pobre se mesclam. ${ }^{20}$ Esse entendimento emerge de uma consciência sistêmica, complexa, inter-relacional, interativa e interdependente e de uma consciência de alteridade que incide em ouvir a voz do outro em suas dimensões cultural, histórica, social e econômica. A consciência inter-relacional e a de alteridade fazem emergir a solidariedade humana para enfrentar a crise planetária em curso. Esta perspectiva apresenta-se como vigilante e crítica à proposta mercadológica para a resolução de problemas de sustentabilidade ambiental. Neste olhar, Ecologia Integral traz uma crítica aguda ao entendimento de deixar o mercado solucionar situações sociais e ambientais e dirigir a história. O mercado, em sua lógica desenvolvimentista, não integra e não ouve a voz vulnerável da terra e nem a voz dos vulneráveis sociais. A perspectiva ecossocial e ecopolítica de Ecologia Integral desafiam à resistência à descartabilidade e ao desperdício, tanto de utensílios, de objetos, como de seres humanos. Na atualidade, é urgente o despertar da consciência da cultura do descartável e do desperdício. Compreender Ecologia Integral consiste em entender a vida em sua dimensão relacionada e deixarse interpelar pelos gritos desesperados dos que habitam a terra, da própria terra e, com destaque especial, dos empobrecidos e dos vulneráveis sociais.

19 PAPA Francisco. Carta Encíclica Laudato Sí. Sobre o cuidado da casa comum, n. $211 .{ }^{18}$ As obras citadas em Referências de Alain Touraine referem-se a esta temática.

20 Destacam-se quatro artigos que ajudam a explicitar e compreender esse tema: BOFF, Leonardo. A encíclica do Papa Francisco não é "verde", é integral. In: MURAD, Afonso; TAVARES, Sinivaldo Silva (Org.). Cuidar da casa comum. São Paulo: Paulinas, p.15-23. BRIGHENTI, Agenor. A evolução do conceito de ecologia no Ensino Social da Igreja. Da Rerum Novarum à Laudato Si'. In: MURAD, Afonso; TAVARES, Sinivaldo Silva (Org.). Cuidar da casa comum. São Paulo: Paulinas, p. 52-64. MAÇANEIRO, Marcial. A ecologia como parâmetro para a ética, a política e a economia. In: MURAD, Afonso; TAVARES, Sinivaldo Silva (Org.). Cuidar da casa comum. São Paulo: Paulinas, p. 73-89. SUSIN, Luiz Carlos. Conversão ecológica: "conversão da conversão". In: MURAD, Afonso; TAVARES, Sinivaldo Silva (Org.). Cuidar da casa comum. São Paulo: Paulinas, p. 40-51. 


\section{A CULTURA BÍBLICO-HEBRAICA E A ECOLOGIA INTEGRAL}

Para se inter-relacionar cultura bíblico-hebraica com ecologia integral, lembram-se três eementos centrais da cultura dos povos do antigo oriente, especificamente aspectos culturais presentes na literatura bíblico-hebraica.

Um primeiro elemento relevante a se lembrar é que os povos, que nos legaram os livros que conhecemos como Velho Testamento ou Antigo Testamento, escreveram esses textos, em sua maioria, antes das reflexões filosóficas que os gregos fizeram a partir dos séculos VI-V antes de Cristo. Tal significa que a antropologia e a visão de mundo que estão presentes nos textos hebreus não se encontram expressas a partir de um dualismo que concebe o ser humano como matéria e não matéria, ou como corpo e alma, ou como corpo e mente..$^{21}$ Em hebraico, Nefesch (pessoa) concebese em sua integralidade. Não se concebe a pessoa desvinculando pensamento da corporeidade. Na cultura hebraica, o pensamento vincula-se com o coração. É o coração que pensa! Os sentimentos e as emoções relacionam-se com os rins. O amor e o ódio, a misericórdia e o rancor, a justiça e a injustiça, a bondade e a maldade, a sabedoria e a ignorância relacionam-se, ao mesmo tempo, com o coração e com os rins. Cingir os rins possui um significado ético-moral de compromisso com a justiça, mantendo o amor, a misericórdia, a bondade e a sabedoria acesos para que, numa visão paradoxal da vida, o ódio, o rancor, a injustiça, a maldade e a ignorância não prevaleçam. A metáfora de separar o trigo do joio, em textos cristãos, integra esse sentido ético-moral. A visão profética, na literatura profética do Antigo Testamento, por exemplo, que sempre é uma visão crítica das injustiças que, especialmente, o Estado monárquico tributário, com suas forças militares, políticas e religiosas, cometia, passa, ao mesmo tempo, pelo olho, ouvido, coração e rins. Na cultura hebraica, o cérebro não é central. Conhecer e ter relações sexuais correspondem-se em muitos textos. Diz-se, por exemplo, que tal homem conheceu tal mulher e deste conhecimento nasce o filho ou a filha. No imaginário cultural bíblico-hebreu, o conhecer, o pensar e o executar não se separam da forma como o pensamento grego vai propor e instaurar a partir, especialmente do século IV, antes de Cristo. Tem-se, portanto, um entendimento cultural em que não se separa pensamento da corporeidade. Cuidar da alma, do espírito, do pensamento confunde-se com o cuidado da corporeidade. Cuidar da pessoa (Nefesch), na cultura hebraica, não significa cuidar do corpo ou do pensamento, em separado. Há uma relacionalidade entre o pensar e o fazer. Prevenia-se a maldade humana, alertando para o que se pensava, pois o que se pensava, o dito e o ato mesclavam-se numa única dimensão de realidade. O maldito e o bendito, a maldição e a bênção, geravam-se de fonte humana em que o dito já era o fato e o ato. Ressalta-se novamente: o imaginário cultural não era o de separar o dito, o pensado, do feito. Fazer e pensar não se disjuntavam.

$21 \quad$ Para se compreender a Antropologia dos povos do antigo oriente, especificamente dos povos que escreveram a Bíblia e o que foi se constituindo como a cultura hebraica, central é a obra: WOLFF, Hans Walter. Antropologia do Antigo Testamento. São Paulo: Hagnos, 1973. 
Um segundo elemento relevante a se destacar do imaginário cultural bíblico-hebraico, para se conceber Ecologia Integral, é a inter-relação entre o Nefesch (pessoa) e o Scheoll (lugar dos mortos), como também a relação entre Adam (Adão, o primeiro homem) e Adamah (terra fértil).

A relação entre pessoa (Nefesch) e lugar dos mortos (Scheoll) mostra-se relevante pelo lugar geográfico onde este se encontra. A pessoa não olha para cima para ver esse lugar. Ela dirige seu olhar para os seus pés. O Scheoll, o lugar dos mortos, encontra-se lá embaixo (!), na terra. O morto não se separa da terra. O lugar dos mortos não se encontra separado da terra. O Sheoll não está nos céus, para além da terra. O lugar divino, endeusado, o lugar de Deus, onde o morto permanece, é a terra. O lugar divino dos mortos situa-se na terra. $\mathrm{O}$ divino e o terreno se mesclam, se confundem e se misturam. A terra se torna sagrada. Por esta razão, na cultura hebraica, a terra não se vende e nem se compra. Jamais a terra será propriedade. A terra é herança. A terra é memória dos pais. Olha-se para a terra, vê-se e ouve-se a memória de justiça dos antepassados.

A relação entre Adam (Adão, o primeiro homem) e Adamah (terra fértil) também merece destaque para se compreender a cultura hebraica no que se refere à relação entre terra e o ser humano. Adam, o primeiro homem, é feito da Adamah, da terra fértil. Não é de qualquer terra que o ser humano é feito. É da terra que produz o alimento para a vida. É da Adamah que Adam é moldado e quando Adam chega ao final de sua vida torna-se novamente Adamah. O ser humano da terra é feito e à terra volta, tornando-se terra e fica junto a Deus em meio à terra.

Esta Antropologia e esta Teologia da cultura hebraica estendem-se a um olhar ecológico e ético de cuidado com a terra. Nesta cultura, qual é o objetivo de Deus ter criado o ser humano? Esta pergunta introduz o terceiro elemento que se procura destacar para se conceber a relação entre Ecologia Integral e cultura hebraica. Focando-se prioritariamente a narrativa mitológica da criação, que se encontra em Gênesis, capítulo 2, o primeiro livro bíblico do Antigo Testamento, nesta narrativa, o ser humano é criado por Deus para cultivar, guardar e cuidar a terra.22 Nesta narrativa, Deus não cria o ser humano para dominar a terra, e sim retomando a ações verbais, o homem e a mulher são criados para cuidar, guardar e cultivar. Sendo Adam moldado da Adamah, ele não pode dominar-se, pisar-se, autodestruir-se, violentar-se. Deus o fez para cuidar-se, para guardar-se e para cultivar-se, pois foi criado da terra e volta à terra.

Sob esta perspectiva, não há separação entre ser humano e a terra. Há uma imbricação, uma mistura, uma relação profunda, uma identificação em que não se concebe a terra como um objeto separado do sujeito humano, ideia que se tornou cultura na modernidade. Em síntese, a cultura

22 Em Gênesis 2,15, as traduções, para o português, dos dois verbos em hebraico, são normalmente realizadas no sentido de cultivar e guardar. Ambos os verbos integram sentidos de cuidado com o jardim de Éden, lugar onde o ser humano é posto por Deus. Ambos os verbos, também, integram o sentido de compromisso para que o jardim seja cultivado, guardado e cuidado. Como o ser vivente foi feito de terra, sendo terra, deve guardar-se, cultivar-se, cuidar-se. 
hebraica integra compreensões desafiadoras para se conceber o ser humano como ser terreno, sendo esta uma das ideias centrais de Hannah Arendt, no livro A Condição Humana, possibilitando entender Ecologia Integral num paradigma em que não se separam elementos que são interdependentes, inter-relacionais e interativos.

\section{CONSIDERAÇÕES FINAIS}

Nesta conclusão, retoma-se a questão central delimitada e informada na introdução deste artigo. Afirma-se, nas considerações iniciais que se pretende, sob uma ótica integrativa, relacionar Hannah Arendt, Ecologia Integral e elementos da cultura hebraica sob o horizonte da defesa da vida. A questão-problema delimita-se na seguinte pergunta: Qual é o núcleo temático pelo qual se possa relacionar a cultura bíblico-hebraica, Hannah Arendt e Ecologia Integral, tendo a defesa da vida como o horizonte dessa relação? Argumenta-se a resposta a esta pergunta focando a diversidade e a pluralidade como núcleos temáticos para estabelecer esta relação. A interação, a interdependência e a inter-relação do diverso e do plural são determinantes para a defesa da vida em sua dimensão e sentido lato (amplo) e stricto (restrito) ao mesmo tempo.

Importante torna-se a lembrar que Hannah Arendt é judia, tendo internalizado, com toda a certeza, muitos elementos que se integram à cultura hebraica. A sua formação vem impregnada, ao mesmo tempo, de cultura ocidental e oriental. Hannah Arendt conhecia profundamente o texto bíblico e toda a cultura hebraica oriental que inspirou uma compreensão relacional entre os seres humanos e entre os seres humanos e a terra. A cultura hebraica, por não ter tido contato com a cultura grega que, de certa forma, impulsionou um entendimento dual da vida, nos dias de hoje ocupa um lugar e uma voz de crítica ao dualismo e ao binarismo presentes na ciência moderna, o que fez com que a terra fosse concebida como objeto a ser conhecido e dominado por um sujeito cognoscente.

Como voz crítica de que a vida inexiste sem relações e a compreensão de que intervenções que eliminam relações são autodestrutivas, significando que o ser humano se conscientiza de sua autoeliminação, a cultura hebraica, e esta cultura, também presente nas reflexões de Hannah Arendt, propicia o surgimento de novas categorias, como a de Ecologia Integral.

Ecologia Integral emerge na ciência como conceito e como categoria de compreensão em que relacionar, inter-relacionar, interfacear, interdepender, auto-organizar, constituem-se ações de um novo paradigma de entendimento da vida humana e da vida em sua dimensão sistêmica inter-relacionada. Neste novo paradigma científico, não se compreende apenas pela analysis, que 
pressupõe separação, disjunção e o controle do conhecido, para poder explicar o que se conhece pela disjunção, mas se supõem relações que não se disjuntam.

Um acento relevante de dimensão sociopolítica de pesquisas que superam o entendimento dual da vida impõe-se hoje como um imperativo, também ético, da superação de uma cultura do desperdício e de uma cultura da descartabilidade. O imaginário de uma cientificidade que separa e não relaciona pode fazer emergir uma cultura em que não se desperdiçam e se descartam apenas os objetos, a fauna e a flora, mas também os seres humanos. Na atualidade, esse risco é grande. A ciência, em nossos dias, tem uma função, também ética²3, de ajudar a fazer emergir uma consciência da imprescindibilidade de manter relações. Sob este horizonte, também ao Direito cabem desafios. Como integrar, num sistema normativo, a defesa da vida em sua dimensão relacional?

\section{REFERÊNCIAS DAS FONTES CITADAS}

ARENDT, Hannah. Origens do totalitarismo: Antissemitismo, imperialismo, totalitarismo. São Paulo: Companhia das Letras, 2012.

ARENDT, Hannah. Eichmann em Jerusalém: um relato sobre a banalidade do mal. Traduzido por José Rubens Siqueira. São Paulo: Companhia das Letras, 2013.

ARENDT, Hannah. Da violência. São Paulo: Companhia das Letras, 2009.

ARENDT, Hannah. A condição humana. 10. ed. Rio de Janeiro: Forense Universitária, 2000.

ARENDT, Hannah. Homens em tempos sombrios. São Paulo: Companhia das Letras, 2008.

BOFF, Leonardo. A encíclica do Papa Francisco não é "verde", é integral. In: MURAD, Afonso; TAVARES, Sinivaldo Silva (Org.). Cuidar da casa comum. São Paulo: Paulinas, 2017.

BRIGHENTI, Agenor. A evolução do conceito de ecologia no Ensino Social da Igreja. Da Rerum Novarum à Laudato Si'. In: MURAD, Afonso; TAVARES, Sinivaldo Silva (Org.). Cuidar da casa comum. São Paulo: Paulinas, 2017.

DERRIDA, Jacques. Torres de Babel. Belo Horizonte: UFMG, 2006.

DERRIDA, Jacques. A farmácia de Platão. 3. ed. São Paulo: lluminuras, 2005.

CERVI, Jacson Roberto; HAHN, Noli Bernardo. A terra pede paz - a emergência do paradigma do cuidado e a superação do paradigma da conquista. In: Revista Internacional de Direito Ambiental. Caxias do Sul: Plenum, n. 15, p.95-116, set/ dez. 2016.

CERVI, Jacson Roberto; HAHN, Noli Bernardo. O Cuidado e a Ecologia Integral. In: Direitos Culturais, Santo Ângelo, v.12, n.27, p. 149-172, maio/ago. 2017.

JONAS, Hans. O Princípio Responsabilidade: ensaio de uma ética para uma civilização tecnológica. Rio de Janeiro: PUC Rio, 2006.

HEIDEGGER, Martin. Serenidade, 1955. Disponível em: www.consciencia.org/heideggerisabel.shtml Acesso em 20.ago.2018.

23 O Princípio Responsabilidade, na perspectiva de Hans Jonas, é desafiador para os dias atuais. Criar uma cultura ética, em que não há apenas uma preocupação míope, de só se responsabilizar pelos já existentes, mas integrar na responsabilidade as gerações vindouras, estas que ainda não existem, consiste num desafio pedagógico de preocupação e cuidado de longo alcance. 
MAÇANEIRO, Marcial. A ecologia como parâmetro para a ética, a política e a economia. In: MURAD, Afonso; TAVARES, Sinivaldo Silva (org.). Cuidar da casa comum. São Paulo: Paulinas,

MORIN, Edgar. A cabeça bem-feita: repensar a reforma, reformar o pensamento. 16. ed. Rio de Janeiro: Bertrand Brasil, 2009.

MORIN, Edgar; ALEXANDRE, Maria D.; DÓRIA, Maria Alice Sampaio. Ciência com consciência. Rio de Janeiro: Bertrand Brasil, 1996.

MORIN, Edgar. $\mathbf{O}$ desafio do século XXI: religar os conhecimentos. Lisboa: Instituto Piaget, 2001.

MORIN, Edgar; PENA-VEGA, Alfredo. O pensar complexo: Edgar Morin e a crise da modernidade. 2. ed. Rio de Janeiro: Garamond, 1999.

OLIVEIRA, Pedro A. Ribeiro de. A difícil integração humana na comunidade de vida da Terra. In: MURAD, Afonso; TAVARES, Sinivaldo Silva (org.). Cuidar da casa comum. São Paulo: Paulinas, p.90-102.

PAPA Francisco. Carta Encíclica Laudato Si . Sobre o cuidado da casa Comum. Roma: Tipografia Vaticana, 2015.

SUSIN, Luiz Carlos. Conversão ecológica: "conversão da conversão". In: MURAD, Afonso; TAVARES, Sinivaldo Silva (Org.).

Cuidar da casa comum. São Paulo: Paulinas, p. 40-51.

TOURAINE, Alain. $\mathbf{O}$ mundo das mulheres. Petrópolis: Vozes, 2007.

TOURAINE, Alain. A busca de si. Rio de Janeiro: Bertrand Brasil Ltda, 2004.

VATTIMO, Gianni. Adeus à verdade. Petrópolis: Vozes, 2009.

VATTIMO, Gianni; GIRARD, René. Cristianismo e Relativismo: Verdade ou fé frágil? Aparecida: Santuário, 2006. WOLFF, Hans Walter. Antropologia do Antigo Testamento. São Paulo: Hagnos, 1973.

RECEBIDO EM: 23/04/2019

APROVADO EM: 10/11/2019 